\title{
Research on the Impact of Financial Development on TFP DEA-Malmquist Index and Hansen Threshold Model Based on Panel Data of Shandong Province, China
}

\section{Fushuai Wang* Ruichao Xi Wenxia Cai}

School of Economics, Shandong University of Technology, Zibo, Shandong, 255022, China

\begin{tabular}{l}
\hline ARTICLE INFO \\
\hline Article history \\
Received: 24 September 2020 \\
Revised: 30 September 2020 \\
Accepted: 9 October 2020 \\
Published Online: 16 October 2020 \\
\hline
\end{tabular}

\section{Keywords:}

TFP

Financial development

Economic growth

Threshold effect

\section{Introduction}

0 ince the Chinese Reform and Opening, China has become the world's second largest economy after about 40 years of comprehensive development under the background of its backward technology and low social productivity. In the past, relying on resource endowments and labor resources advantages, Chinese total economic growth momentum was rapid. Unfortunately, since the beginning of this century, the emergence of population aging has made demographic dividend of China disappear. Furtherly, the limited availability of natural re-

\section{ABSTRACT}

Shandong's TFP growth is higher than Chinese average, but the growth rate has slowed in recent years, appearing the phenomenon that the growth momentum of Shandong's TFP is insufficient. Using DEA-Malmquist Index to measure Shandong's TFP growth rate, empirical research from the perspective of financial development finds that financial scale, efficiency of financial institutions, fiscal intervention, and scale of foreign capital utilization have significant nonlinear effects on the growth of TFP. Furtherly, through threshold analysis, the efficiency of financial institutions has a significant threshold effect on TFP growth. Financial scale and fiscal intervention are the main core variables that affect the growth of TFP under the threshold effect, and they have the same effect direction on TFP before and after the threshold value. However, the effect intensity of these two core variables on TFP is different.

\footnotetext{
*Corresponding Author:

Fushuai Wang,

School of Economics, Shandong University of Technology, No. 88 Communist Youth League Road, Zibo, Shandong, 255022, China;

E-mail:m17852739772@163.com.

Fund Project:

This paper was supported by The National Social Science Fund of China-Research on the Quality Improvement Mechanism of Heterogeneous Enterprises' Export Products under the Global Value Chain Division of Labor System (Project No.: 18BJL100) and Shandong Province Social Science Planning Research Project- Research on Optimizing Operation Mechanism of Shandong Equity Investment Guidance Fund (Project No.: 17CJRJ10).
} 
the economic benefits generated by financial development continue to increase, and the speed of social and economic growth has continued to accelerate (Qinxian Bai, 2000) ${ }^{[2]}$. From the perspective of the exploitation and utilization of financial resources, financial development can increase the level of TFP, thereby providing capital and technology for economic growth. It remains to be seen whether excessive intervention or suppression of financial development will hinder the process of the TFP's growth, slowing down economic growth. Explore, which urgently need further investigation.

Basically, under the established conditions of production factors, which were put into production, the additional benefits generated by technological progress contribute the most to economic growth (Robert M. Solow, 1957) ${ }^{[3]}$. What's more, with the development of the regional economy, the phenomenon that economic growth depends on the progress of TFP is obvious (Rioja F. and N. Valev, 2004) ${ }^{[4]}$. According to relevant researches, although a part of driving force has come from factor inputting, more importantly, the decisive driving force of China's economic growth in recent years has come from the improvement of TF (Gang Yi, Gang Fan, Yan Li, $2003)^{[5]}$. In addition to the proven factors affecting the growth of TFP,- such as technology level, the quantity and quality of labors, and the stability of social development (Chamarbagwala, Rubiana, 2006) ${ }^{[6]}$ - financial development, fiscal decentralization, and the use of foreign capital also have a significant impact on China's TFP growth (Huiling Wang, Xiuyuan Peng, 2017) ${ }^{[7]}$ (Hong Lei, 2019) ${ }^{[8]}$. In the process of economic development, financial development promotes industrial upgrading and optimization, and financial institutions guide capital to projects with higher yields, so that high-quality industries can obtain sufficient guarantee funds of technical innovation, which makes TFP and investment return rates will continue to increase. Theoretically, taking its advantage of the basic mechanism that affects the efficiency of capital allocation, finance improves capital structure, accelerates capital accumulation, and promotes technological innovation, which promote economic grow reasonably and rapidly. On the contrary, in fact, the development of finance may passively follow economic growth. In other words, there is no general conclusion between the both. Furthermore, the importance of financial development acting on economic growth might have been overemphasized (Yong Zhao, Da Lei, 2010) ${ }^{[9]}$.

From the perspective of the economic cycle, financial development has a non-linear, "U-shaped", relationship with TFP growth. When financial development exceeds the "U-shaped" bottom threshold value, the further development of finance will significantly promote the growth of $\mathrm{TFP}^{[10]}$. In the economic contraction stage, financial development has a restraining effect on the growth of TFP. Yet, in the economic expansion stage, financial development encourages the growth of TFP. That is to say financial development has a "threshold effect" on the growth of TFP. After the threshold value is crossed, financial development promotes the growth of total factor productivity. But when financial development is below the threshold value, the growth of TFP is more dependent on other growth source.

Under the requirements of the era of high-quality economic growth and supply-side structural reforms, Shandong Province, China has transferred its own advantages to focus on building a new model of "blue and yellow-economy" development. Although it has achieved remarkable rewards in recent years, there are still some economic and social issues, for example, inefficient use of financial funds, the not yet complete financial institution system, and the problem of overcapacity in the old industries. Taking into account analysis above, this paper studies the impact mechanism of financial development acting on TFP, during the process that exploring whether financial development has a "threshold effect" on the growth of TFP in Shandong Province, China. Above all, using DEA-Malmquist index method, measure the TFP growth rate of Shandong Province and other provinces across China, to make horizontal and vertical comparisons. And then, based on the Hansen threshold model, a comprehensive analysis of the impact mechanism of Shandong Province's financial development indicators on the growth of TFP is carried out. The ultimate goal of this paper is, from the perspective of finance development, to provides references for the further TFP growth of the regions whose situations are similar to Shandong Province, China.

\section{Measurement of TFP Based on DEA-Malm- quist Index Method}

\subsection{Construction of Theoretical Model}

Based on the distance function, set the Malmquist index, which refers to the technical function- TECHNOLO$\mathrm{GY}(\mathrm{t})$ - in the $\mathrm{t}$ period and the $\mathrm{t}+1$ period.

Malmquist $_{t}\left(X_{t}, Y_{t}, X_{t+1}, Y_{t+1}\right)=\frac{d i s \tan \boldsymbol{e}_{t}\left(X_{t+1}, Y_{t+1}\right)}{\operatorname{dis} \tan \boldsymbol{e}_{t}\left(X_{t}, Y_{t}\right)}$

Among them, $\left(\mathrm{X}_{\mathrm{t}}, \mathrm{Y}_{\mathrm{t}}\right)$ is the combination vector of factor input and total output, and distance $_{t}$ is the distance 
function with reference to TECHNOLOGY(t). In order to, referring to the method of Caves et al. (1982) ${ }^{[11]}$, the geometric average value of formula (1) is used to measure the TFP growth rate, to reduce the fluctuations caused by selection of the time span of the time series data.

$T F P=\left[\text { Malmquist }_{t}\left(X_{t}, Y_{t}, X_{t+1}, Y_{t+1}\right) \bullet \text { Malmquist }_{t+1}\left(X_{t}, Y_{t}, X_{t+1}, Y_{t+1}\right)\right]^{\frac{1}{2}}$

Incorporating formula (1) into formula (2), obtain the calculation model of TFP growth rate.

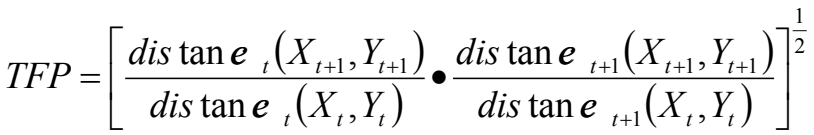

Drawing lessons from the research of Goldsmith and Levine (1997) ${ }^{[12]}$, it is the scale indicators of financial development and the efficiency indicators of financial institutions that are incorporated into the model, to construct a model used to value economic growth. Based on the "Snow model", construct a model of the impact of financial development on economic growth, which incorporate financial scale, efficiency of financial institutions, fiscal intervention, and scale of foreign capital utilization into the multiple combination function of technological progress.

$Y_{i, t}=A_{i, t}\left(\right.$ scale $_{i, t}$, efficiency $_{i, t}$, finance $_{i, t}$, fdi $\left._{i, t}\right) \bullet f_{i, t}\left(K_{i, t}, L_{i, t}\right)$

After introducing the random error term, divide $\mathrm{f}_{\mathrm{i}, \mathrm{t}}\left(\mathrm{K}_{\mathrm{i}, \mathrm{t}}\right.$, $\mathrm{L}_{\mathrm{i}, \mathrm{t}}$ ) on both sides of the equation (4), and then take the logarithm to get the theoretical model.

$\ln \frac{Y_{i, t}}{f_{i, t}\left(K_{i, t} L_{i, t}\right)}=\beta_{0}+\beta_{1} \ln V B_{i, t}+\beta_{2} \ln L B_{i, t}+\beta_{3} \ln F I V_{i, t}+\beta_{4} \ln F I L_{i, t}+\beta_{5} \ln F E_{i, t}+\beta_{6} \ln F D I_{i, t}+c$

After further deformation, the measurement formula of this chapter is obtained.

$\ln T F P_{i, t}=\beta_{0}+\beta_{1} \ln V B_{i, t}+\beta_{2} \ln L B_{i, t}+\beta_{3} \ln F I V_{i, t}+\beta_{4} \ln F I L_{i, t}+\beta_{5} \ln F E_{i, t}+\beta_{6} \ln F D I_{i, t}+c$

\subsection{Regression Estimation of DEA-Malmquist Index}

Through the DEA-Malmquist index model, the TFP growth rate of Shandong Province, China from 2003 (base year) to 2017 is calculated.
Table 1. Summary of DEA-Malmquist Index in Shandong Province, China from 2003 to 2017

\begin{tabular}{|c|c|c|c|c|c|}
\hline Index & $\begin{array}{c}\text { Technical } \\
\text { Efficiency } \\
\text { Index }\end{array}$ & $\begin{array}{c}\text { Technology } \\
\text { Progress } \\
\text { Index }\end{array}$ & $\begin{array}{c}\text { Pure Effi- } \\
\text { ciency Index }\end{array}$ & $\begin{array}{c}\text { Scale } \\
\text { Efficiency } \\
\text { Index }\end{array}$ & $\begin{array}{c}\text { TFP } \\
\text { Growth } \\
\text { Rate Index }\end{array}$ \\
\hline 2003 & 1.000 & 1.000 & 1.000 & 1.000 & 1.000 \\
\hline 2004 & 1.069 & 1.026 & 1.068 & 1.001 & 1.097 \\
\hline 2005 & 0.967 & 1.059 & 0.967 & 1.000 & 1.025 \\
\hline 2006 & 1.039 & 1.031 & 1.039 & 1.001 & 1.072 \\
\hline 2007 & 1.007 & 1.029 & 1.007 & 1.000 & 1.036 \\
\hline 2008 & 1.029 & 1.036 & 1.028 & 1.000 & 1.066 \\
\hline 2009 & 1.005 & 1.018 & 1.005 & 1.000 & 1.023 \\
\hline 2010 & 0.986 & 1.007 & 0.986 & 1.000 & 0.993 \\
\hline 2011 & 0.979 & 0.980 & 0.979 & 1.000 & 0.959 \\
\hline 2012 & 1.001 & 0.982 & 1.001 & 1.000 & 0.984 \\
\hline 2013 & 1.154 & 0.784 & 1.213 & 0.952 & 0.906 \\
\hline 2014 & 0.997 & 1.007 & 1.000 & 0.997 & 1.005 \\
\hline 2015 & 1.015 & 1.072 & 1.000 & 1.015 & 1.089 \\
\hline 2016 & 0.986 & 1.119 & 1.000 & 0.986 & 1.103 \\
\hline 2017 & 0.995 & 0.856 & 1.000 & 0.995 & 0.852 \\
\hline
\end{tabular}

Using the same principle, calculate the 2003-2017 TFP growth rate of other 30 provinces, municipalities, and autonomous regions in China except Shandong Province.

Table 2. Summary of 2013-2017 TFP growth rate of China's provinces, municipalities, and autonomous regions

\begin{tabular}{|c|c|c|c|c|c|}
\hline Year & 2013 & 2014 & 2015 & 2016 & 2017 \\
\hline Area & 0.984 & 1.014 & 1.094 & 1.108 & 0.845 \\
\hline Beijing City & 0.956 & 1.009 & 1.075 & 1.126 & 0.879 \\
\hline Tianjin City & 0.909 & 0.951 & 1.058 & 1.117 & 1.025 \\
\hline Hebei Province & 0.885 & 0.940 & 1.025 & 1.053 & 0.985 \\
\hline Shanxi Province & 0.890 & 1.018 & 1.084 & 1.103 & 0.762 \\
\hline Inner Mongolia Autonomous & & & & & \\
\hline Region & 0.894 & 1.003 & 1.114 & 0.898 & 0.921 \\
\hline Liaoning Province & 0.888 & 0.987 & 1.061 & 1.078 & 0.836 \\
\hline Jilin Province & 0.931 & 1.001 & 1.064 & 1.066 & 0.844 \\
\hline Heilongjiang Province & 0.959 & 1.025 & 1.135 & 1.169 & 0.867 \\
\hline Shanghai City & 0.721 & 0.973 & 1.115 & 1.145 & 0.883 \\
\hline Jiangsu Province & 0.983 & 0.983 & 1.109 & 1.141 & 0.877 \\
\hline Zhejiang Province & 0.885 & 0.983 & 1.087 & 1.127 & 0.891 \\
\hline Anhui Province & 0.972 & 0.998 & 1.076 & 1.111 & 0.874 \\
\hline Fujian Province & 0.902 & 0.973 & 1.048 & 1.119 & 0.852 \\
\hline Jiangxi Province & 0.855 & 0.981 & 1.059 & 1.089 & 0.873 \\
\hline Henan Province & 0.887 & 0.993 & 1.071 & 1.096 & 0.869 \\
\hline Hubei Province & 0.938 & 0.999 & 1.083 & 1.101 & 0.837 \\
\hline Hunan Province & 0.851 & 0.992 & 1.072 & 1.080 & 0.868 \\
\hline Guangdong Province & 0.902 & 0.987 & 1.063 & 1.096 & 0.790 \\
\hline Guangxi Zhuang Autonomous & & & & & \\
\hline Region & 0.910 & 0.983 & 1.067 & 1.091 & 0.863 \\
\hline Hainan Province & 0.921 & 1.011 & 1.112 & 1.144 & 0.870 \\
\hline Chongqing City & 0.835 & 1.023 & 1.080 & 1.114 & 0.880 \\
\hline Sichuan Province & 0.957 & 1.022 & 1.120 & 1.105 & 0.882 \\
\hline Guizhou Province & 0.959 & 1.007 & 1.078 & 1.078 & 0.857 \\
\hline Yunnan Province & 0.908 & 1.001 & 1.095 & 1.148 & 0.842 \\
\hline Tibet Autonomous Region & 0.868 & 0.983 & 1.034 & 1.085 & 0.885 \\
\hline Shanxi Province & 0.941 & 0.980 & 1.003 & 1.066 & 0.845 \\
\hline Gansu Province & 0.917 & 0.957 & 1.074 & 1.071 & 0.809 \\
\hline Qinghai Province & 0.945 & 0.986 & 1.007 & 1.046 & 0.869 \\
\hline Xinjiang Uygur Autonomous & & & & \\
\hline Region & & & & \\
\hline & & &
\end{tabular}


Based on the above calculation and analysis, a comparison chart of the growth trend of TFP between Shandong Province and the China's average is drawn.

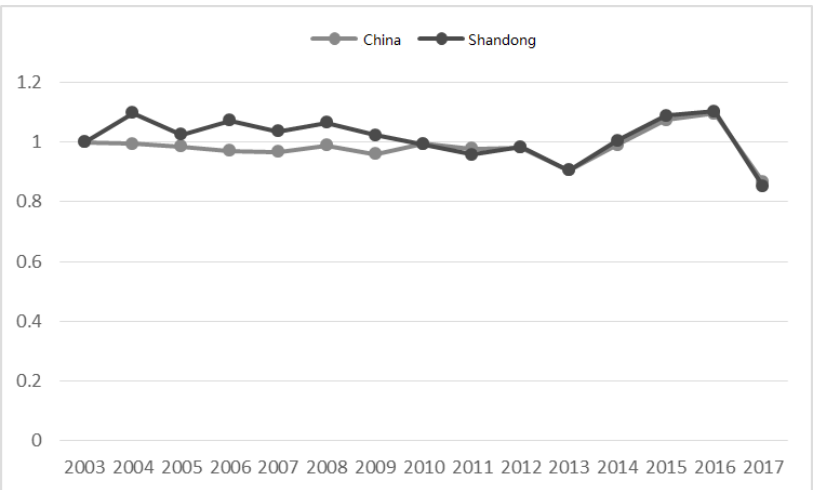

Figure 1. The growth rate of TFP across China and Shandong Province from 2003 to 2017

It's shown that since 2003, TFP growth rate of Shandong Province has been ahead of the national average. However, since 2010, the speed of Shandong's TFP growth rate has slowed down, and sometimes even lower than the national average growth rate. After a four-year growing period from 2013 to 2016, the growth rate of TFP in both the China's average and Shandong Province fell to about 0.8 point in 2017, which shows the characteristics of insufficient growth momentum of TFP.

\section{Analysis on the Growing Effect of Finan- cial Development's Influence on TFP}

\subsection{Variable Setting and Data Processing}

Table 3. Selection list of indicators and variables

\begin{tabular}{|c|c|}
\hline Indicators & variables \\
\hline Total economic output (Y) & Real GDP \\
\hline Labor factor input (L) & Capital stock \\
\hline Capital factor input (K) & $\begin{array}{c}\text { Total face value of currency, deposits and } \\
\text { circulating financial instruments (vb, lb) }\end{array}$ \\
\hline Financial scale (scale) & tions (fiv, fil) \\
\hline $\begin{array}{c}\text { Efficiency of financial } \\
\text { institutions (efficiency) }\end{array}$ & $\begin{array}{c}\text { Total current account of financial instu- } \\
\text { tions (fe) }\end{array}$ \\
\hline $\begin{array}{c}\text { Fiscal intervention (fi- } \\
\text { nance) }\end{array}$ & $\begin{array}{c}\text { Total current accitu- } \\
\text { tions (fdi) }\end{array}$ \\
\hline $\begin{array}{c}\text { Scale of foreign capital } \\
\text { utilization (fdi) }\end{array}$ & \begin{tabular}{c} 
Total current account of finstitu- \\
\hline
\end{tabular} \\
\hline
\end{tabular}

Among the indicators and variables, the conversion of real GDP is obtained by price deflation based on the GDP price deflation index of 1978 as the base year. For the technical treatment of the capital stock, the perpetual inventory method is used for calculation- defining 2003 as the base year, firstly, the fixed asset investment (I) is converted into a constant price in 2005 using the fixed asset investment price index. Secondly, referring the method of
Haojie Shan (2008) ${ }^{[13]}$, calculate the base year's capital stock $\left(\mathrm{K}_{2003}=\mathrm{I}_{2004} /(\eta+\delta)\right)$. Among them, $\eta$ is the average growth rate of fixed assets from 2003 to 2017 , and $\delta$ is the depreciation rate, which is $9.6 \%$ according to the study result of Jun Zhang et al. (2004) ${ }^{[14]}$. After all, calculate the capital stock of each year $\left(\mathrm{K}_{\mathrm{t}+1}=(1-\delta) \mathrm{K}_{\mathrm{t}}+\mathrm{I}_{\mathrm{t}+1}\right)$ through the perpetual inventory method.

\subsection{Data Source and Statistical Description}

GDP and GDP price index of each province comes from National Bureau of Statistics of China, and the GDP of each city in Shandong Province comes from the statistical yearbook of each place. Part of the data of the employed population of each province comes from the China Labor Statistics Yearbook, and that of each city in Shandong Province comes from the statistical yearbook of prefectures and cities. The fixed asset investment amount and fixed asset investment price index of each province come from the China Economic Statistics Database, and the same variables of each city in Shandong Province come from the EPS Statistical Database. Both total face value of currency, deposits and circulating financial instruments and the total amount of current accounts of financial institutions in all cities in Shandong Province are derived from Shandong Statistical Yearbook, Shandong Financial Statistical Yearbook and annual audit reports of financial institutions. Local fiscal expenditures are derived from local cities' Financial Statistics Yearbook, and the total amount of foreign capital utilization comes from the China Economic Statistics Database.

The selected time span of the variables is from 2003 (base period) to 2014, with a total of 31 observation targets, that nominal GDP, fixed asset investment, price index, and employed population of all provinces, municipalities and autonomous regions across China. The statistical characteristics are as follows.

Table 4. Statistical description of total output and input factors of production

\begin{tabular}{|c|c|c|c|c|c|}
\hline Vars & Mean & Median & Max & Min & $\begin{array}{c}\text { Standard } \\
\text { Deviation }\end{array}$ \\
\hline Real GDP & 14885.13 & 10823.01 & 89705.23 & 185.09 & 14933.03 \\
\hline $\begin{array}{c}\text { GDP price defla- } \\
\text { tion index }\end{array}$ & 535.61 & 544.62 & 660.59 & 380.67 & 89.99 \\
\hline $\begin{array}{c}\text { Fixed asset } \\
\text { investment }\end{array}$ & 9736.52 & 6352.70 & 55202.72 & 133.96 & 10027.41 \\
\hline $\begin{array}{c}\text { Fixed asset } \\
\text { investment price } \\
\text { index }\end{array}$ & 102.60 & 102.16 & 113.28 & 96.00 & 3.27 \\
\hline $\begin{array}{c}\text { Employed popu- } \\
\text { lation }\end{array}$ & 461.63 & 402.02 & 1973.28 & 17.37 & 329.25 \\
\hline
\end{tabular}

The selection time span of the variables of Shandong Province is from 2004 to 2017, a total of 14 years, that fi- 
nancial scale, efficiency of financial institutions, financial intervention, and scale of foreign capital utilization. The observations are 17 prefecture-level cities in Shandong Province, China, a total of 17 groups. As follows are the statistical characteristics of the variables.

Table 5. Statistical description of variables of panel regression and threshold regression

\begin{tabular}{|c|c|c|c|c|c|}
\hline Vars & Mean & Median & Max & Min & $\begin{array}{c}\text { Standard } \\
\text { Deviation }\end{array}$ \\
\hline $\ln$ TFP & 1.7471 & 1.7499 & 2.2879 & 0.8176 & 0.2575 \\
\hline $\ln$ VB & 16.7115 & 16.7435 & 18.9251 & 14.2922 & 0.9416 \\
\hline $\ln$ LB & 15.8166 & 16.2640 & 18.7845 & 5.7389 & 2.5252 \\
\hline $\ln$ FIV & 16.0770 & 16.0088 & 18.8500 & 13.9705 & 1.0114 \\
\hline $\ln$ FIL & 15.7839 & 15.6875 & 18.6469 & 13.6961 & 1.0196 \\
\hline $\ln$ FE & 13.6233 & 13.6540 & 16.2365 & 11.5772 & 0.9537 \\
\hline $\ln$ FDI & 9.6920 & 9.7319 & 13.2490 & 2.5649 & 1.4850 \\
\hline
\end{tabular}

\subsection{Regression of Panel Data Model}

Based on the theoretical model set above, regression estimates are made on the multiple effects of financial scale, efficiency of financial institutions, fiscal intervention, and scale of foreign capital utilization acting on TFP. The results are as follows.

Table 6. List of regression results of panel model

\begin{tabular}{|c|c|c|c|c|}
\hline & & Dependent & ble: $\ln \mathrm{TFP}$ & \\
\hline $\begin{array}{l}\text { Independent } \\
\text { variables }\end{array}$ & (1) & (2) & (3) & (4) \\
\hline $\ln \mathrm{VB}$ & 0.040 & -0.107 & -0.109 & -0.095 \\
\hline & $(0.020)$ & $(0.052)$ & $(0.053)$ & $(0.053)$ \\
\hline $\ln \mathrm{LB}$ & 0.032 & 0.026 & 0.028 & -0.029 \\
\hline & $(0.011)$ & $(0.010)$ & $(0.010)$ & $(0.010)$ \\
\hline ln FIV & & 0.692 & 0.647 & 0.620 \\
\hline & & $(0.126)$ & $(0.145)$ & $(0.146)$ \\
\hline $\ln$ FIL & & -0.551 & -0.550 & -0.572 \\
\hline & & $(0.118)$ & $(0.120)$ & $(0.120)$ \\
\hline $\ln \mathrm{FE}$ & & & 0.043 & 0.066 \\
\hline & & & $(0.060)$ & $(0.061)$ \\
\hline $\ln$ FDI & & & & 0.030 \\
\hline & & & & $(0.018)$ \\
\hline Intercept & 0.569 & 0.713 & 0.811 & 0.759 \\
\hline & $(0.354)$ & $(0.330)$ & $(0.359)$ & $(0.364)$ \\
\hline $\begin{array}{l}\text { Number of } \\
\text { observations }\end{array}$ & 238 & 238 & 238 & 238 \\
\hline R-sq & 0.251 & 0.394 & 0.352 & 0.361 \\
\hline
\end{tabular}

Through the regression estimation of the panel mod$\mathrm{el}$, it is found that, under the sole impact of the financial scale, the financial scale promotes the growth of TFP, but, under the combined effect of other factors, financial scale plays a restraining effect, which shows that the impact of financial scale on TFP is affected by other factors, such as efficiency of financial institutions, fiscal intervention, and foreign capital. What's more, it is the asset business of financial institutions that has a restraining effect on the growth of TFP, which shows the current financial institutions' allocation of funds, risk diversification, and control of investment yields do not serve technological innovation well. In addition, fiscal intervention and foreign capital have an incentive effect on the growth of TFP. That is to say, fiscal intervention has played a role in supporting the growth of TFP, and foreign capital also positively promotes TFP through the domestic financial market.

\section{Threshold Effect of Financial Development on TFP}

\subsection{Regression Estimation of Threshold Model}

Related studies have found that there may be structural mutations in the effect of financial development on TFP growth, that is, there may be a certain non-linear relationship. Further research has found that financial development has such a threshold effect on TFP, and the threshold values of different observation objectives are hard various. According to Hansen Panel Threshold Model, the model hypothesis of this chapter is proposed.

$$
\operatorname{TFP}_{i, t}=\mu_{i}+\beta_{1}^{\prime} X_{i, t} \bullet I\left(q_{i, t} \leq \gamma\right)+\beta_{2}^{\prime} X_{i, t} \bullet I\left(q_{i, t}>\gamma\right)+\varepsilon_{i, t}
$$

Among the symbols, I is the indicative function, $\mathrm{q}$ is the threshold variable, $\gamma$ is the threshold value, and $\varepsilon$ obeys probability distribution independently and identically. Taking the above theoretical model assumptions as a basis, financial scale, efficiency of financial institutions, fiscal intervention, and scale of foreign capital utilization are defined as threshold variable individually in the following section, and threshold effect analysis is carried out.

Divide the section into 400 parts, and bootstrap sampling 200 times. After defining threshold variables individually, the remaining three variables are as core explanatory variables affected by threshold variables, and furtherly, the model is single threshold. Eliminating 1\% of abnormal results, the threshold estimator and its confidence interval are regressed. 
Table 7. Threshold estimation and confidence interval regression results

\begin{tabular}{|c|c|c|c|}
\hline \multicolumn{4}{|c|}{ Threshold estimator (Level=95) } \\
\hline Model & Threshold & Lower & Upper \\
\hline Th-1 & $3.2428 \times 10^{7}$ & $2.5451 \times 10^{7}$ & $3.9540 \times 10^{7}$ \\
\hline
\end{tabular}

The estimated value of the threshold effect is $3.2428 \times 10^{7}$, and the confidence interval is the upper and lower limits of $95 \%$. The significance test of the threshold effect was carried out, on the threshold variable and the core variables affected by the threshold variable respectively, which is found that the threshold effect test is not significant when the financial scale, fiscal intervention, and scale of foreign capital utilization are used as the threshold variable. The threshold effect is only the most significant, when the efficiency of financial institutions is used as the threshold variable, and financial scale and fiscal intervention are respectively as the core variables affected by the threshold variable. The threshold effect test value is as follows.

Table 8. Summary of threshold effect test values

\begin{tabular}{|c|c|c|c|c|c|c|c|}
\hline \multicolumn{7}{|c|}{ Threshold effect test (bootstrap=300) } \\
\hline rX & RSS & MSE & Fstat & Prob & Crit10 & Crit5 & Crit1 \\
\hline scale & $1.10 \times 10^{5}$ & 766.85 & 112.03 & 0.00 & 16.22 & 19.07 & 33.44 \\
\hline finance & $1.17 \times 10^{5}$ & 815.51 & 91.65 & 0.00 & 25.91 & 31.91 & 44.61 \\
\hline
\end{tabular}

According to the significance test of the threshold effect, we can see that the threshold effect test statistics are estimated to be $1.10 \times 10^{5}$ and $1.17 \times 10^{5}$, which are far greater than the upper confidence limits that $10 \%, 5 \%$, and $1 \%$ (RSS $>>$ Crit10, RSS $>>$ Crit5, RSS $>>$ Crit1). Simultaneously, the $\mathrm{P}$ value is 0 , indicating that the threshold effect is significant. Based on the above analysis, the regression estimation of the fixed effects threshold model is carried out.

Table 9. List of regression estimation results of threshold model

\begin{tabular}{|c|c|c|}
\hline \multirow{3}{*}{$\begin{array}{l}\text { Threshold } \\
\text { variable: } \\
\text { efficiency }\end{array}$} & \multicolumn{2}{|c|}{ Dependent variable: TFP } \\
\hline & \multicolumn{2}{|c|}{ Core explanatory variables } \\
\hline & scale & finance \\
\hline \multirow[t]{2}{*}{ scale } & $\begin{array}{c}\text { No threshold effect: } \\
0.0546465 \\
(0.0130583)\end{array}$ & \multirow{2}{*}{$\begin{array}{c}0.0078849 \\
(0.0070515)\end{array}$} \\
\hline & $\begin{array}{c}\text { Threshold effect: } 0.095521 \\
(0.0148566)\end{array}$ & \\
\hline efficiency & $\begin{array}{c}0.000013 \\
\left(2.13 \times 10^{-6}\right)\end{array}$ & $\begin{array}{c}0.000004 \\
(0.000001)\end{array}$ \\
\hline \multirow[t]{2}{*}{ finance } & \multirow{2}{*}{$\begin{array}{c}6.35 \times 10^{-7} \\
\left(7.00 \times 10^{-7}\right)\end{array}$} & $\begin{array}{c}\text { No threshold effect: } \\
4.96 \times 10^{-7} \\
\left(7.3910^{-7}\right)\end{array}$ \\
\hline & & $\begin{array}{c}\text { Threshold effect: } 0.0000521 \\
\left(5.75 \times 10^{-6}\right)\end{array}$ \\
\hline
\end{tabular}

\begin{tabular}{|c|c|c|}
\hline \multirow{2}{*}{ fdi } & -0.003565 & -0.0010016 \\
& $(0.0001356)$ & $(0.0001592)$ \\
\hline \multirow{2}{*}{ Intercept } & 242.4392 & 263.6385 \\
& $(6.968664)$ & $(7.456707)$ \\
\hline R-sq & 0.5546 & 0.4988 \\
\hline
\end{tabular}

The results of threshold regression estimation found that efficiency of financial institutions has a significant threshold effect on TFP growth, and it is financial scale and fiscal intervention that are the main influencing factors in the threshold effect. With the improvement of the efficiency of financial institutions, financial scale has also increased its role in the growth of TFP, indicating the flow of funds to entities for technological innovation lays on the improvement of efficiency of financial institutions. What's more, as the efficiency of financial institutions crosses the threshold value, the role of fiscal intervention in promoting TFP has also been strengthened, indicating financial institutions can effectively transfer fiscal expenditures to enterprises, through the financial market, which allows enterprises to carry out technological upgrades and innovations, thereby enhancing TFP growth rate.

\subsection{Robustness Test}

In order to test whether there are significant differences between individuals in time and cross-section, this chapter analyzes the sample individuals longitudinally and horizontally by setting the F statistic, thereby determine whether the model is a mixed effect or an individual fixed effect is more reasonable and effective. The F statistic is constructed by the ratio of the residual sum of squares of the unrestricted regression model and the restricted regression model. The following assumptions are made for the $\mathrm{F}$ statistic.

$\mathrm{H}_{0}$ : The intercepts of different individuals are the same (the real model is a mixed regression).

$\mathrm{H}_{1}$ : Individuals have different intercept terms (the real model is an individual effect regression).

The formula of $\mathrm{F}$ statistic is following.

$F=\frac{(R R S S-U R S S) /(N-1)}{U R S S /(N T-N-K+1)} \sim F(N-1, N(T-1)-K+1)$

Among these symbols, RRSS is the residual sum of squares of the mixed effects regression model, URSS is the residual sum of squares of the individual fixed effects regression model, $\mathrm{N}$ is the sample size, and $\mathrm{K}$ is the number of estimated parameters in the unconstrained model. If the null hypothesis $\mathrm{H}_{0}$ holds, the statistic $\mathrm{F}$ obeys the $\mathrm{F}$ distribution with degrees of freedom (N-1, N(T-1)-K+1).

The regression estimation result of the mixed effects model is as follows. 
$\operatorname{lnTFP}=0.62-0.12 \ln \mathrm{VB}+0.01 \ln \mathrm{LB}+0.58 \ln \mathrm{FIV}-0.38 \ln -$ FIL-0.04lnFE $+0.02 \ln F D I$

$$
\begin{aligned}
& \begin{array}{llllll}
(2.00)(-3.36) & (1.08) & (5.40) & (-4.16) & (-0.74) & (1.55)
\end{array} \\
& \mathrm{R}^{2}=0.25 \text {, } \\
& \mathrm{SSEr}=11.50347
\end{aligned}
$$

From the above, it can be seen that the residual sum of squares of the mixed effects model is RRSS=SS$\mathrm{Er}=11.50347$.

The regression estimation result of the individual fixed effects model is as follows.

LnTFP $=1.24-0.07 \ln V B+0.04 \ln \mathrm{B}+0.69 \ln F I L-0.79 \ln -$ FIV $+0.17 \ln F E+0.02 \ln F D I+0.04 \mathrm{D}_{1}+0.27 \mathrm{D}_{2}+\ldots+0.16 \mathrm{D}_{17}$

$$
\begin{aligned}
& \begin{array}{llllll}
(2.43) & (-1.40) & (2.72) & (4.11) & (-5.41) & (2.22)
\end{array} \\
& \mathrm{R}^{2}=0.49 \text {, } \\
& \mathrm{SSEr}=7.829949
\end{aligned}
$$

In the formula (10), the definition of dummy variables $D_{1}, D_{2}, \ldots, D_{17}$ is following.

$D_{i}\left\{\begin{array}{l}1, \mathrm{D}_{\mathrm{i}} \text { belongs to the } \mathrm{i}^{\text {th }} \text { sample individual }(\mathrm{i}=1,2, \ldots, 17) \\ 0, \text { Else }\end{array}\right.$

From the regression result, it can be seen that the residual sum of squares of the individual fixed effects model is URSS $=\mathrm{SSEr}=7.829949$.

According to formula (8), $\mathrm{F}=8.41 \mathrm{~F} \sim \mathrm{F}(13,238)$, $\mathrm{F}=8.41>\mathrm{F}_{0.05}(13,238)=1.792$. Therefore, the impact mechanism of financial development acting on TFP is such an individual fixed effect model, which shows that the effect of financial development in Shandong Province, China on the growth of TFP is more significantly affected by different regions than it is affected by time factor. In other words, the financial development of various cities in Shandong Province, China is uneven, and there is a relatively large gap in the role of finance in the growth of TFP between cities of Shandong. It causes that, under the influence of regional factors, finance promotes TFP growth significantly more than economic cycle factor.

\section{Conclusions and Recommendations}

\subsection{Main Conclusion}

Firstly, Shandong Province's TFP is higher than the Chinese national average, but in recent years the growth momentum has been insufficient, with uneven development among cities of Shandong. Since 2010, the gap between Shandong's TFP growth rate and that of Chinese national average has gradually decreased, or even converged, showing the characteristics of lagging growth. In order to achieve the goal, that high-quality regional economic growth, Shandong Province, China not only needs to consolidate the driving role of the source of TFP growth, but also maintain the gap in the role of finance in promoting TFP growth among cities.

Secondly, it is efficiency of financial institutions that has a significant threshold impact on Shandong's TFP, but that of financial scale, fiscal intervention, and scale of foreign capital. When efficiency of financial institutions is defined as the threshold variable, financial scale and fiscal intervention are the main explanatory variables, which have a positively significant threshold impact on the growth of TFP. That's to say, the TFP of Shandong Province, China is non-linearly affected by the efficiency of financial institutions, where financial scale and fiscal intervention play a major role in TFP.

Thirdly, the financial scale has a positive effect on TFP before and after the efficiency of financial institutions reaches the threshold value, but the strength after the threshold value is greater than before. That shows, when the regional financial scale is underdeveloped, relying solely on the growth of financial scale will increase investable capital and promote the growth of TFP. Fortunately, as the regional financial institution system continues to mature, the scale of financial institutions will lead to the strengthening of the functions of financial institutions, the efficiency of financial institutions will be improved, and the degree of effect on TFP will also be strengthened.

Finally, fiscal intervention also promotes TFP growth, and its impact will increase after efficiency of financial institutions reaches the threshold value, which shows fiscal intervention can support the growth of TFP when the regional financial institution system is not fully sound or low in efficiency, but the intensity is not visible. After only being improved, efficiency of financial institutions will promote the intensity of fiscal intervention to TFP growth, such as local bonds or stateowned enterprise investment and financing, through capital allocation and risk diversification of financial institutions.

\subsection{Related Suggestions}

The research results of this paper show that, in order to play the role of financial development in promoting the growth of TFP, not only is it necessary to increase financial scale, but to coordinate financial development and fiscal intervention. To have sufficient liquidity in the financial market, the purpose for that is to meet the needs of investment and financing of enterprises, improving the services of financial institutions, and to enhances 
the ability of financial services to satisfy the entities' innovation and creation. Otherwise, to achieve the maximum impact on TFP growth, it is imminent to adjust the structural relationship between financial development and fiscal intervention in different economic periods, timely and scientifically. However, in recent years, the TFP growth momentum of Shandong Province, China has been insufficient. Hence, at present, Shandong Province, China and other regions with similar characteristics are supposed to take parallel measures simultaneously, to deepen financial development and financial liberalization, alleviate financial repression, and promote inclusive finance. In order to achieve smooth economic transformation and high-quality growth, promote the formation of a healthy financial ecology, and strengthen the positive impact of financial development on the growth of TFP

First, although the total financial scale of Shandong Province, China is large, there are still some problems, such as homogenization of financial instrument types and unitary structure of financial institutions. Similar types of financial instruments and single structure financial institutions are combined into a range of financial structures with the same characteristics, which creates troubles for companies that a single structure of investment and financing, and higher financing risks, resulting in inaccurate capital flow direction and capital maturity. Due to the nature, some financial funds are left idle, deposited, and even become bad assets. In the future, regions with similar characteristics should focus on expanding the types of financial instruments, optimizing the financial structure, and forming a multi-level, multi-structure, and multi-featured financial structure, to revitalize the accumulated capital that has ever been bad assets. Second, the financing structure of physical enterprises in Shandong Province is mostly indirect financing by commercial bank credit business, which inhibits other financial intermediaries. Not only does the unity of the financial intermediary system fail to adopt the demand of technological innovation input, in the upgrading of enterprises, but increases the financing risks of enterprises, which causes the increasingly anxious problem of financial restraint. In the future, Shandong Province, China and regions with similar characteristics should aim to optimize the financial intermediary system, whose specific measures are appropriately loosening controls on capital flows, rationally adjusting the scope of implementation of the guiding credit plan, reducing financial institution approval restrictions, and deepening the development of financial liberalization, to improve the efficiency of financial institutions in serving entities. In addition, to provide enterprises with diversified financing channels, while allocating funds through credit rationing, efforts should be urgently made to promote the construction of direct financing markets. Third, although Shandong Province, China has a relatively large economic aggregate, the proportion of small or medium-sized enterprises is far more than that of large-scale enterprises. To accelerate the growth of TFP in the whole society, the basic role of small or medium-sized enterprises must cannot be ignored. However, recently, as some financial institutions have closed the branch structure of lagging cities in order to save costs in some cities of all over the world in the same situation, the requirement of financing threshold for small or medium-sized enterprises has become higher and higher, which has created obstacles for small or medium-sized enterprises in terms of innovation investment and spatial layout. Then, in the process of deepening the structural reform of the financial supply side, Shandong Province, China should strengthen the protection of small or medium-sized enterprises, encourage and urge financial institutions to reduce the financing constraints on the innovative investment, promote the construction and development of inclusive finance, and use the power of fiscal intervention to support the TFP of whole regional society in a timely manner. What's more, regions with similar characteristics rest of the word can also accept the same policy suggestions.

\section{References}

[1] Minjie Dong, Yongmei Liang. Sources of China's Economic Growth from 1978 to 2010: A Nonparametric Decomposition Framework [J]. Economic Research Journal,2013(05):17-32.

[2] Qinxian Bai. Re-discussion on the theory of financial sustainable development based on the theory of financial resources_— paradigm shift, theoretical innovation and method change [J]. Studies of International Finance,2000(02):7-14.

[3] Robert M. Solow. Technical Change and the Aggregate Production Function [J]. The Review of Economics and Statistics, 1957(39):312-320.

[4] Rioja F. and N. Valev. Finance and the Sources of Growth at Various Stages of Economic Development $[\mathrm{J}]$. Economic Inquiry, Western Economic Association International, 2004: 42.

[5] Gang Yi, Gang Fan, Yan Li. Theoretical Thinking on China's Economic Growth and Total Factor Productivity $[\mathrm{J}]$. Economic Research Journal,2003(08):13-20+90. 
[6] Chamarbagwala, Rubiana. The Role of Social Norms in Child Labor and Schooling in India [J]. Caepr Working Papers, 2006(2006-016).

[7] Huiling Wang, Xiuyuan Peng. Nonparametric Analysis of Factors Affecting TFP in Chinese Provinces [J]. Statistics \& Decision,2017(22):126-130.

[8] Hong Lei. China's OFDI reverse technology spillover, financial development and total factor productivity $[\mathrm{J}]$. Modern Economic Research,2019(08):75-84.

[9] Yong Zhao, Da Lei. Financial development and economic growth: productivity promotion or capital formation [J] The Journal of World Economy. ,2010,33(02):37-50.

[10] Yong Ma, Hang Zhang. How do financial factors affect total factor productivity? $[\mathrm{J}]$. Chinese Review of Finance Studies,2017,9(05):1-17+123.

[11] Caves, D.W., Christensen, L.R., Diewert, W. E.. The Economic Theory of Index Numbers and the Measurement of Input and Output, and Productivity [J]. Econometrica, 1982(50), 1393-1414.

[12] Levine R.. Financial Development and Economic Growth: Views and Agenda [J]. Journal of Economic Liteature, 1997(35).

[13] Haojie Shan. Re-estimation of China's Capital Stock K: 1952-2006 [J]. The Journal of Quantitative \& Technical Economics, 10 .

[14] Jun Zhang, Guiying Wu, Jipeng Zhang. Estimation of China's Inter-provincial Material Capital Stock: 1952-2000[J]. Economic Research Journal,2004(10):35-44. 